\title{
A PERCEPÇÃO AMBIENTAL DOS GRADUANDOS DA DISCIPLINA DE DIREITO AMBIENTAL EM RELAÇÃO AS ÁREAS DE PRESERVAÇÃO AMBIENTAL
}

\author{
$\underline{\text { Raquel Trevizan }}{ }^{1}$, Ana Maria Thielen Merck ${ }^{2}$
}

\footnotetext{
${ }^{1}$ Acadêmica do Curso de Engenharia Florestal, UFSM, Santa Maria-RS, raquel_trevi@hotmail.com; ${ }^{2}$ Professora Adjunta, Departamento de Biologia, UFSM, Santa Maria-RS, anathielenmerck@gmail.com;
}

Palavras-chave: meio ambiente, código florestal e pesquisa qualitativa.

$\mathrm{Na}$ elaboração de estratégias de educação ambiental em educação informal devem ser feitos estudos prévios sobre a percepção ambiental da comunidade a ser estudada. O presente trabalho tem como objetivo avaliar o conhecimento de conceitos técnicos relacionados com a área ambiental (Áreas de Preservação Permanente, Reserva Legal e o Código Florestal) de graduandos da disciplina de Direito Ambiental, dos cursos de Direito e Ciências Biológicas, na Universidade Federal de Santa Maria. A pesquisa de caráter qualitativo teve como base um questionário misto, de sete perguntas. Os resultados foram analisados e apresentados em porcentagem. Os graduandos em Ciências Biológicas mostram um conhecimento conceitual de 16\% para Áreas de Preservação Permanente (APP) e 32\% deles tem conhecimento de sua importância. $97 \%$ dos graduandos em Ciências biológicas tem conhecimento da importância ecológica da Reserva Legal (RL) e $100 \%$ para as Matas Adjacentes. Ao serem questionados se as alterações nas Reservas Legais previstas pelo novo Código Florestal podem influenciar a vida do proprietário de terra $74 \%$ responderam que sim, porém, apenas $42 \%$ dos graduandos tem noção de quais são essas consequências. Os graduandos em Direito apresentaram resultado de $29 \%$ para o conhecimento conceitual de Áreas de Preservação Permanente e $44 \%$ deles tem conhecimento de sua importância. Entretanto, ao serem questionados sobre a importância ecológica da Reserva Legal $76 \%$ dos graduandos mostraram que tem conhecimento sobre o assunto e $82 \%$ para Matas Adjacentes. Quando questionados se as alterações nas Reservas Legais previstas pelo novo Código Florestal podem influenciar a vida do proprietário de terra $79 \%$ dos graduandos responderam que sim, mas $62 \%$ não souberam responder quais são essas consequências. Comparando os dois cursos observa-se que em relação às Áreas de Preservação Permanente (23\%) e as mudanças no Código Florestal (31\%) as porcentagens médias do grupo foram bastante baixas, porém, foram observados melhores resultados relacionados ao conhecimento de Matas Adjacentes (90\%) e Reserva Legal (86\%). Frente à importância da preservação do meio ambiente para manutenção dos recursos naturais, é necessário ampliar a base conceitual dos conhecimentos relacionados aos recursos naturais e sua importância nos futuros profissionais nas áreas das Ciências Biológicas e Direito para torná-los aptos a tomarem decisões importantes diretamente ligadas a este tema.

\section{INTRODUÇÃO}

A todo momento são tomadas decisões políticas e economicas que afetam diretamente o meio ambiente e as populações. Sabendo que este é um bem de uso comum, portanto, a titularidade é o povo; todos temos o direito de decidir sobre o uso do bem ambiental, como está determinado pela Constituição Federal no Art. 225: "Todos têm direito ao meio ambiente 


\section{Revista Eletrônica em Gestão, Educação e Tecnologia Ambiental REGET/UFSM (e-ISSN: 2236-1170).}

ecologicamente equilibrado, bem de uso comum do povo e essencial à sadia qualidade de vida, impondo-se ao Poder Público e à coletividade o dever de defendê-lo e preservá-lo para as presentes e futuras gerações". Mas para isso é necessário ter conhecimento da função e importância do mesmo na vida cotidiana.

A percepção ambiental pode ser definida como uma tomada de consciência do ambiente pelo homem. Cada indivíduo percebe o ambiente, reage e responde a este de forma diferenciada e individual. As respostas ou manifestações sobre ele estão relacionadas principalmente às vivencias históricas e sociais desses indivíduos (MERCK, 2009). É um processo mental de interação do indivíduo com o meio ambiente circundante; esta interação se dá através de mecanismos perceptivos propriamente ditos e principalmente através de processos cognitivos (DEL RIO, 1999).

A tomada de consciência do ambiente pelo homem surge através da sensibilização, do mesmo, apartir do momento em que este passa a perceber a importância da relação entre homem - ambiente e quanto esta afeta sua qualidade de vida. Apartir desta sensibilização os indivíduos serão capazes de agir criticamente e transformar a realidade onde vivem. Para que isto ocorra é necessário um conhecimento teórico básico de como funciona as relações entre o homem e o seu meio.

Um dos aspectos ambientais mais polêmicos da atualidade basileira é a mudança do Código Florestal que será aprovado pelo Senado em 2012. Em parte, devido ao desconhecimento da população da importância do Código para a manutenção do equilíbrio do meio ambiente e na preservação dos recursos naturais. Recursos naturais estes, que são a produção básica da economia brasileira.

O Código Florestal visa a conservação das florestas e outros ecossistemas naturais para assegurar uma boa qualidade de vida à todos os brasileiros, vetando a ocupação urbana ou agrícola em áreas de risco e garantindo serviços ambientais básicos, como a produção de água, a regulação do ciclo das chuvas e dos recursos hídricos, a proteção da biodiversidade, a polinização, o controle de pragas, o controle do assoreamento dos rios, inundações, deslizamentos de terra e o equilíbrio do clima. É o código que determina a obrigação de se proteger áreas mais suscetíveis a erosão - Áreas de Preservação Permanete (APP), e manter uma parcela de vegetação nativa no interior das propriedades rurais - Reserva Legal (RL) (SOS Florestas, 2011). Considerando que estão sendo discutidas mudanças para o mesmo, nos cabe questionar se todos tem conhecimento suficiente para a tomada de decisão, diante da importância de preservar os recursos naturais para manutenção da vida, especialmente os discentes dos cursos de Direito e Ciências Biológicas em formação.

O presente estudo teve como objetivo avaliar o conhecimento e a importância dos temas relacionados ao Código Florestal, na disciplina de Direito Ambiental em graduandos de Ciências Biológicas e Direito da Universidade Federal de Santa Maria.

\section{METODOLOGIA}

Este trabalho foi conduzido como uma pesquisa de percepção ambiental desenvolvida na disciplina de Educação Ambiental, no Departamento de Biologia da Universidade Federal de Santa Maria (UFSM), Santa Maria, RS, Brasil. Na pesquisa, de caráter qualitativo, foi elaborado um questionário misto (perguntas abertas e fechadas) com sete perguntas relacionadas ao Código Florestal: conceito e importância da Área de Preservação Permanente, da Reserva Legal e das 


\section{Revista Eletrônica em Gestão, Educação e Tecnologia Ambiental \\ REGET/UFSM (e-ISSN: 2236-1170).}

Matas adjacentes e, as mudanças envolvidas no Código Florestal e suas consequências para os proprietários de terras. 0 universo da pesquisa foram 65 alunos da disciplina de Direito Ambiental da UFSM, que estão cursando o $7^{\circ}$ semestre das graduações em Direito (34 alunos) e Ciências Biológicas (31 alunos). Os resultados foram analisados e apresentados em porcentagem.

\section{RESULTADOS E DISCUSSÃO}

Na avaliação do conhecimento conceitual de Áreas de Preservação Permanente (APP) $16 \%$ dos graduandos em Ciências Biológicas e $28 \%$ dos graduandos em Direito selecionaram a alternativa correta: "São margens de rios, cursos d'água, lagos, lagoas e reservatórios, topos de morros e encostas com declividade elevada, cobertas ou não por vegetação nativa", enquanto que $39 \%$ e $18 \%$, respectivamente, definem APP apenas quando as áreas estão cobertas por vegetação. Porém, $45 \%$ dos graduando em Ciências biológicas e 54\% em Direito selecionaram a definição de Reserva Legal: "É uma área localizada no interior da propriedade ou posse rural que deve ser mantida ou reflorestada com a sua cobertura vegetal original" considerando-a equivalente a Área de Preservação Permanete, como pode ser visto na Figura 1.

\section{Ciências biológicas}

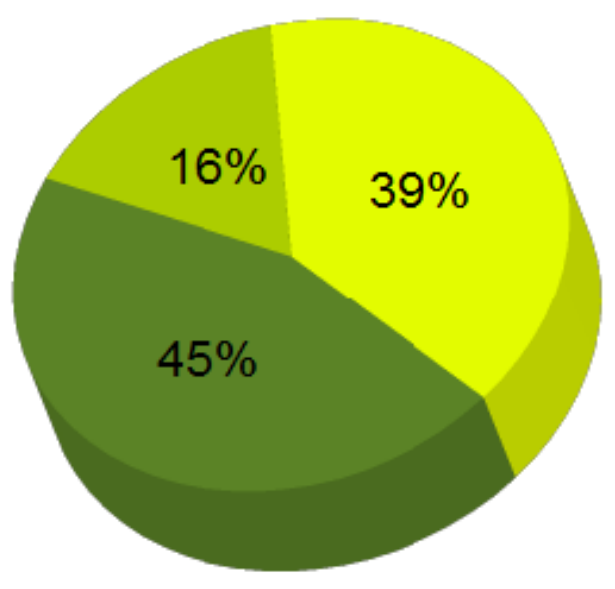

Direito

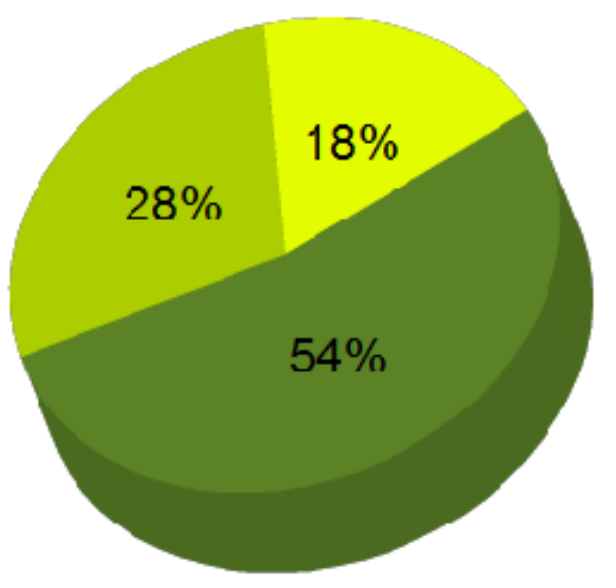

Legenda:

Tem conhecimento

Define por Reserva Legal

Considera APP apenas com vegetação

Figura 1: Conhecimento conceitual de Áreas de Preservação Permanente (APP).

Em relação a importância das APPs 32\% dos graduandos em Ciências Biológicas e $44 \%$ dos graduandos em Direito tem conhecimento, entretanto, ao serem questionados sobre a importância ecológica da Reserva Legal 97\% dos alunos das Ciências Biológicas e 76\% do Direito mostraram que tem conhecimento sobre o assunto.

Os resultados analisados mostram que a maioria dos graduandos tem um melhor conhecimento da importância da Reserva Legal em relação a importância das Áreas de Preservação 


\section{Revista Eletrônica em Gestão, Educação e Tecnologia Ambiental REGET/UFSM (e-ISSN: 2236-1170).}

\section{Permanente.}

Entretanto ao ser analisado o conhecimento conceitual ocorreram equívocos de equivalência entre Reserva Legal e Áreas de Preservação Permanente, o que faz com que a função da Reserva Legal que é "Assegurar o uso econômico sustentável dos recursos naturais, proporcionar a conservação e a reabilitação dos processos ecológicos, promover a conservação da biodiversidade, abrigar e proteger a fauna silvestre e a flora nativa" e, a função das Áreas de Preservação Permanente que é "Preservar os recursos hídricos, a paisagem, a estabilidade geológica, a biodiversidade, o fluxo gênico de fauna e flora e de proteger o solo e assegurar o bem estar da população humana" (SOS Florestas, 2011) fique diluida num grande contexto de preservação ambiental.

Para Matas Adjacentes todos (100\%) dos graduandos das Ciências Biológicas conhecem a sua importância e $82 \%$ dos graduandos em Direito. Conceitua-se Matas Adjacentes como Áreas de Preservação Permanente. Os graduandos possuem melhor conhecimento da importância das Matas adjacentes em relação aos topos de morros e encostas com declividade elevada, que também compõem as Áreas de Preservação Permanente.

As Matas adjacentes (mata ciliar ou zona ripária) são as margens e cabeceiras de drenagens dos cursos d'água que caracterizam-se por ser uma interface entre os ecossitemas terrestres e aquáticos, com habitats de extrema dinâmica, diversidade e complexidade. Desempenham um dos mais importantes serviços ambientais: manutenção dos recursos hídricos, em termos de vazão e qualidade da água, assim como do ecossistema aquático (LIMA, 2006).

Quando questionados se as alterações nas Reservas Legais previstas pelo novo Código Florestal podem influenciar a vida do proprietário de terra, $74 \%$ dos graduandos da Biologia e $79 \%$ dos graduandos do Direito responderam que sim, mas $42 \%$ dos graduandos das Ciências Biológicas e $62 \%$ dos graduandos do Direito não souberam responder quais são essas consequências.

O desconhecimento das consequências nas alterações das Reservas Legais no novo Código Florestal tem a sua base na formação academica dos dois cursos. No curso de Ciências Biológicas a temática ambiental é explorada em várias disciplinas permitindo que os graduandos tenham um melhor conhecimento das consequências das alterações (58\%) em relação ao curso de Direito (38\%); entretanto a falta de uma disciplina específica na grade curricular que trate do manejo de áreas silvestres faz com que somente tenham este conhecimento de forma genérica, e não relacionem as consequências socioambientais de sua alteração (42\%). Uma possível explicação para o desconhecimento das consequências das alterações do Código nos graduandos de Direito (62\%) é que na grade curricular do curso a temática ambiental pertinente ao Código é explorada somente nas disciplinas de Direito Ambiental e Direito Agrário. A complexidade da temática ambiental faz com que estas disciplinas sejam insuficientes para uma melhor compreensão das consequências ambientais e sociais das alterações do Código Florestal. Ver Tabela 1. 


\section{Revista Eletrônica em Gestão, Educação e Tecnologia Ambiental} REGET/UFSM (e-ISSN: 2236-1170).

Tabela 1: Questionário de percepção ambiental sobre assuntos pertinente ao Código Florestal

\begin{tabular}{|c|c|c|}
\hline QUESTIONAMENTOS & BIOLOGIA & DIREITO \\
\hline $\begin{array}{l}\text { Conhecimento da importância das Áreas de Preservação } \\
\text { Permanente (APP) }\end{array}$ & $32 \%$ & $44 \%$ \\
\hline Conhecimento da importância ecológica da Reserva Legal & $97 \%$ & $76 \%$ \\
\hline $\begin{array}{l}\text { Conhecimento da importância da manutenção das matas } \\
\text { adjacentes }\end{array}$ & $100 \%$ & $82 \%$ \\
\hline $\begin{array}{c}\text { Influência para os proprietários de terras com as mudanças na } \\
\text { Reserva Legal previstas pelo novo Código Florestal }\end{array}$ & $74 \%$ & $79 \%$ \\
\hline $\begin{array}{l}\text { Não tem conhecimento de quais são as consequências para os } \\
\text { proprietários de terras }\end{array}$ & $42 \%$ & $62 \%$ \\
\hline
\end{tabular}

A Figura 2 mostra as quais as principais mudanças que estão sendo discutidas no Código Florestal na percpeção dos graduandos de Ciência Biológicas e Direito.

Quando questionados sobre as principais mudanças que estão sendo discutidas no Código Florestal $36 \%$ dos graduandos em Ciências biológicas e 33\% dos graduandos em Direito mencionaram a redução das Áreas de Preservação Permanente como a alteração mais importante do novo Código. Se comparamos com a Figura 1 onde ocorre uma sobreposição dos conceitos de Área de Preservação Permanente e Reserva Legal por grande parte dos graduandos de ambos os cursos pode-se levar a crer que a escolha pela redução das Áreas de Preservação Permanente como alteração mais importante do Código não está vinculado com o conhecimento teórico e conceitual mas, talvés, por ter uma abordagem maior nos meios de comunicação de massa.

Em relação a Redução da Reserva Legal, que está diretamente relacionada com a redução das Áreas de Preservação Permanente, ocorre uma grande variação entre os cursos: Ciências biológicas (36\% ) Direito (10\%) Essa alteração no Código que pretende reduzir a área da Reserva LegaL de $80 \%$ para 50\% em áreas de floresta e de 35\% para 20\% em áreas de Cerrado, na Amazônia Legal, quando o Zoneamento Ecológico Econômico indicar. A redução da RL também poderá se dar em áreas com vegetação "para fins de regularização ambiental" e, não apenas para fins de recomposição florestal, como esta previsto na lei em vigor hoje (SOS Florestas, 2011). Esta variação pode ser explicada, em parte, pelo conhecimento maior da importância ecológica das Reservas Legais pelos graduandos de Ciências Biológicas (97\% Tab.1), entretanto, se comparados os porcentuais da importância da Reserva Legal (97\%) com os da redução da Reserva Legal (36\%) pode-se observar uma dificuldade dos graduandos das Ciências Biológicas em transpor o conhecimento teórico em conhecimento prático e aplicável, e mensurar os efeitos socioambientais da redução da Reserva Legal. Este é um aspecto relevante uma vez que uma das atribuições dos Biólogos é o manejo de áreas silvestres.

Os graduandos de Direito consideraram a redução da Reserva Legal (10 \%) com a modificação mais importante do Código; comparando com os porcentuais de sua importância ecológica (76 \%) nota-se um descompasso entre o conhecimento conceitual teórico e as consequências socoambientais e economicas da aplicação deste conhecimento (62\%) 


\section{Revista Eletrônica em Gestão, Educação e Tecnologia Ambiental REGET/UFSM (e-ISSN: 2236-1170).}

desconhecem suas consequências para os produtores de terra (Tab.1). O simples conhecimento teórico sobre Reserva Legal não permite perceber a implicação do uso do mesmo. Como este item tem implicações econômicas e políticas de curto e longo prazo, e tem sido amplamente divulgado muitos graduandos acabam fazendo uma opção emocional e não científica.

19\% dos graduandos em Ciências Biológicas e 17\% dos graduandos em Direito mencionaram a redução e a descaracterização das Áreas de Preservação Permanente como uma importante modificação do Código. No novo Código Florestal está previsto uma redução dos atuais 30 metros para 15 metros de faixa marginal e a demarcação das matas ciliares protegidas a partir do leito menor do rio e não do nível maior do curso d'água como no Código anterior. Um dos pontos mais polêmicos do novo Código, a anistia aos crimes ambientais que é o fim da obrigação de se recuperar áreas desmatadas ilegalmente até 22 de julho de 2008, incluindo Áreas de Preservação Permanete - topos de morros, margens de rios, restingas, manguezais, nascentes, montanha e terrenos ingremes (SOS Florestas, 2011) não foi considerado por ambos os cursos, sendo os porcentuais semelhantes (Fig.2). Entretanto, esta modificação ampliará a redução das Áreas de Preservação Permanente e de Reserva Legal além de atuar diretamente sobre a biodiversidade local.

Assim como a Anistia aos crimes ambientais, a redução e descaracterização das APPs é uma importante mudança do novo Código que deve ser analisada e discutida com base no conceito do que é uma Área de Preservação Permanente e principalmente na sua função e importância ecológica para as área adjacentes e as implicações sociais e políticas nas comunidades que nelas vivem. Os graduandos, dos dois cursos, apresentaram uma média de $84 \%$ de desconhecimento das consequências das reduções destas áreas e as suas consequências socioambientais para a região onde se encontram; Entretanto ao comparamos com os porcentuais de conhecimento conceitual destas Áreas (97\% Ciências Biológicas) e (76\% Direito) pode-se inferir que embora tenham o conhecimento conceitual das APP e sua importância ecológica não conseguem aplicar o conceito e mensuar as consequências socioambientais da redução destas áreas.

A Isenção de Reserva Legal para imóveis com até 4 módulos fiscais em todo o país é pouco conhecida entre os graduandos, pois apenas $2 \%$ dos graduandos em Ciências biológicas e $6 \%$ dos graduandos em Direito mencionaram essa alteração prevista pelo novo Código Florestal. A mudança preve o fim da necessidade de recuperar a Reserva Legal para propriedades com até 4 módulos fiscais, dependendo da região, o módulo fiscal varia entre 5 e 100 hectares (SOS Florestas, 2011). E, a compensação de áreas desmatadas em um estado da federação por áreas de floresta plantadas em outros estados ou a conservação e plantio de mata ciliar em bacias hidrográficas que permite compensar o dano ambiental em outra área, isentando completamente da obrigação de recuperar efetivamente o impacto local e, também, dar ao proprietário de terra a opção de fazer a compensação em dinheiro (SOS Florestas, 2011), não foi mencionada por nenhum graduando dos dois cursos.

Tendo conhecimento da grande biodiversidade brasileira e principalmente da importância da preservação dos biomas brasileiros como fonte de recursos naturais, essas mudanças previstas para novo Código Florestal deixam em situação de risco as condições para sobrevivência de muitas espécies da flora e da fauna. E, como pode ser observado pelo resultado na pesquisa há um baixo conhecimento dessas alterações pelos graduandos de ambos os cursos.

Os graduandos que não tem conhecimento das alterações previstas pelo novo Código Florestal corresponderam a $5 \%$ nas Ciências biológicas e $17 \%$ no Direito. Esta variação pode ser explicada pela disciplina de Direito Ambiental estar em curso no momento da pesquisa e vários aspectos legais referentes ao Codigo Florestal não terem sido abordados até o momento da 


\section{Revista Eletrônica em Gestão, Educação e Tecnologia Ambiental \\ REGET/UFSM (e-ISSN: 2236-1170).}

pesquisa, uma vez que $17 \%$ dos graduandos de Direito não respondeu sobre as modificações do novo Código. Este porcentual maior dos graduandos de Direito que desconhecem as alterações do novo Código perfazem 34\% dos graduandos de Direito analisados. (Figura 2)

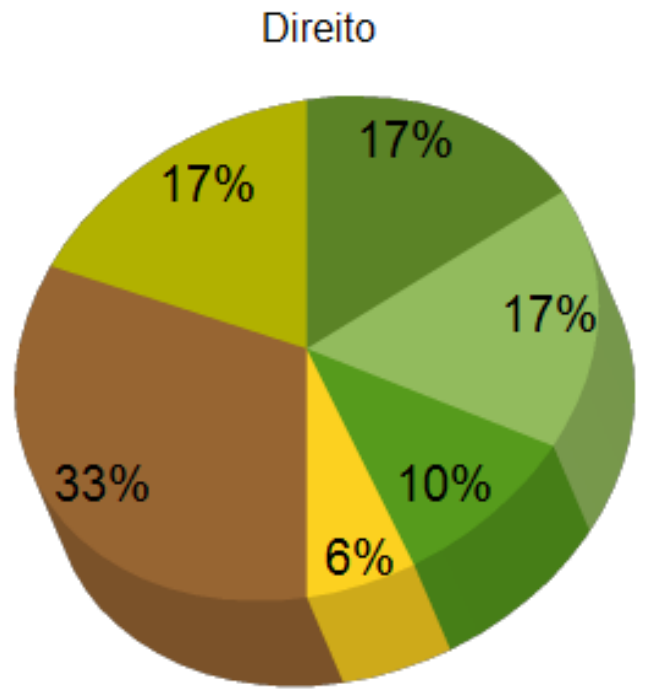

\section{Ciências biológicas}

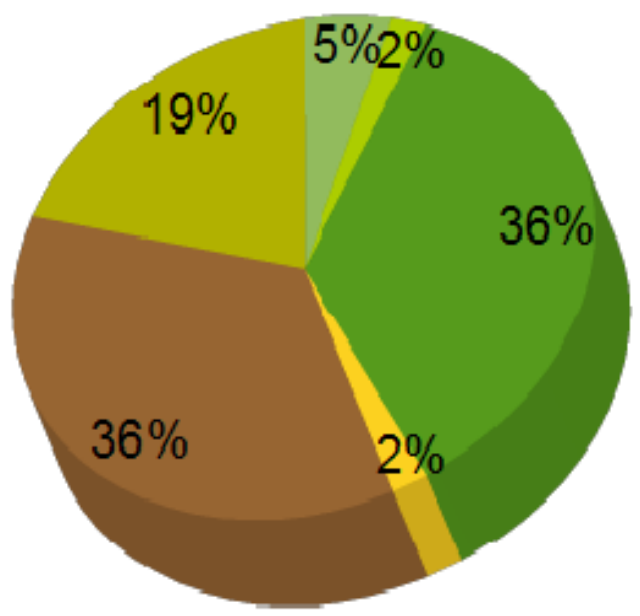

Legenda:

Anistia de multas

Redução da Área de Preservação Permanente Isenção de Reserva Legal

Redução da Reserva Legal

Compensação de áreas

Não tem conhecimento

Não respondeu

Figura 2: Principais mudanças no Código Florestal

\section{CONCLUSÃO}

Frente a importância da preservação do meio ambiente para a manutenção dos recursos naturais é necessário ampliar a base conceitual dos conhecimentos relacionados ao recursos naturais e principalmente salientar as conseqüências para o ambiente e a sociedade civil de modificações legais sobre os mesmos.

Nos cursos de graduação devido a extensa grade curricular e a metodologia didática disciplinar faz com que assuntos de importância vital para a sociedade e pertinentes as cursos sejam pouco explorado pelos docentes, ou quanto explorados estão relacionados fundamentalmente a base conceitual. Cabe ao graduando explorar esta base conceitual e compreender as conseqüências de sua aplicação na vida cotidiana.

Áreas interdisciplinares, como o meio ambiente, devido a sua complexidade não podem ser 


\section{Revista Eletrônica em Gestão, Educação e Tecnologia Ambiental \\ REGET/UFSM (e-ISSN: 2236-1170).}

trabalhadas de forma unidisciplinar pois somente o conhecimento conceitual não permite avaliar as conseqüências da sua aplicação.

Ao avaliar a percepção dos graduandos de Ciência Biológicas e Direito do 7ạ semestre, cursos estes diretamente relacionados ao meio ambiente, um por ter atribuição de desenvolver o manejo em áreas silvestre e outro por legislar na área ambiental, buscou-se perceber se os mesmos tinham base conceitual para decidir cientificamente e não pela emoção às modificações previstas para o novo Código Florestal.

Os graduandos, em ambos os cursos, mostram uma base conceitual sobre os temas discutidos no novo Código Florestal, mas apresentam dificuldade de aplicá-los ou identificar as conseqüências socio-ambiental dos mesmos.

Mudanças no Código Florestal que trazerem modificações significativas para a economia e sociedade devem ser discutidas em bases científicas projetando a longo prazo as consequêcias para a sociedade. A mídia tem importante papel na divulgação destas conseqüências. Em um mundo multidisciplinar e midiático, o simples conhecimento conceitual não permite o seu uso, especialmente em áreas de interface, como meio ambiente.

Os cursos de Ciências Bilógicas e Direito devem oportunizar aos graduando o exercício da interdisciplinaridade e de aplicação de conceitos teóricos na vida cotidiana. Tal exercício tornariaos aptos a tomar decisões profissionais ligadas ao meio ambiente, uma vez que estão inseridos nele.

\section{REFERÊNCIAS BIBLIOGRÁFICAS}

Art. 225 da Constituição da República Federativa do Brasil de 1988. Capítulo VI - Do Meio Ambiente.

Brasília, DF.

Disponível em: http://www.planalto.gov.br/ccivil 03/constituicao/constitui\%C3\%A7ao.htm Acesso em: 10 de novembro de 2011.

DEL RIO \& OLIVEIRA (org.). Percepção ambiental: a experiência Brasileira.

São Paulo, SP: Studio Nobel, 1999.

LIMA, Walter de Paula \& ZAKIA, Maria José Brito (org.). As florestas plantadas e a água. Implementando o conceito da microbacia hidrográfica como unidade de planejamento. São Carlos, SP: RiMa, 2006. Capítulo VI (pág 77 e 78).

MERCK, A.M.T. Medologologias interdisciplinares em Educação Ambiental Caderno Didatico, UFSM/ETIC, 2009.

SOS Florestas - Disponível em: http://www.sosflorestas.com.br/o que fazer.php Acessado em: 12 de agosto de 2011. 